\title{
On the anomalous shapes of native copper crystals from the Michigan Copper Country
}

\author{
Jean-Claude Boulliard ${ }^{1}$, Jérôme Aléon ${ }^{2}$, and Eloïse Gaillou ${ }^{3}$ \\ ${ }^{1}$ Collection de minéraux, Institut de Minéralogie, de Physique des Matériaux et de Cosmochimie, \\ Case 53, 4 Place Jussieu, 75252 Paris CEDEX 05, France \\ ${ }^{2}$ Institut de Minéralogie, de Physique des Matériaux et de Cosmochimie, Sorbonne Université, \\ Muséum National d'Histoire Naturelle, CNRS UMR 7590, IRD CP 52, 61 rue Buffon 75005 Paris, France \\ ${ }^{3}$ MINES ParisTech, PSL Research University, Musée de Minéralogie, \\ 60 boulevard Saint-Michel, 75006 Paris, France
}

Correspondence: Eloïse Gaillou (eloise.gaillou@mines-paristech.fr)

Received: 9 September 2020 - Revised: 30 December 2020 - Accepted: 12 January 2021 - Published: 29 January 2021

\begin{abstract}
For over a century, the anomalous shapes of Michigan copper crystals from the Michigan Copper Country have been acknowledged. They are well known by mineral collectors and curated in museums from all around the world; still, their particular habits remain enigmatic. These natural crystals do not seem to follow crystal shape theories, based on the internal three-dimensional crystal structure. In this article, we offer a unique perspective on the formation of Michigan copper crystals.

Firstly, we review the most common theories of crystal shapes. Then, taking into account the surface reconstructions induced by adsorbed oxygen, detected by ultra-high vacuum techniques, we present evidence of a strong correlation between these oxygen-induced surface reconstructions and the anomalous shapes. Finally, in order to understand why these shapes are not found in copper at other localities, oxygen dosing was performed using NanoSIMS on different natural copper crystals as a preliminary investigation. The higher oxygen content found in the Michigan copper crystal studied compared to others supports the influence of adsorbed oxygen on the anomalous crystal shapes. This result shows which mechanisms could modify crystal shapes and allow the development of strategies to monitor them, due to the presence of oxygen impurities. This new find is of great importance in shape-dependent catalysis, sensor characteristics, or other properties of material such as nanocrystals.
\end{abstract}

\section{Introduction}

Copper changed the face of humanity some 7000 years ago and is still now one of the most important metals of our modern society. Its applications range from thermal and electrical conductor material and building material to machine components, among many others. The Michigan Copper Country located in the Keweenaw Peninsula was a unique and economically important copper deposit: it was the first worldwide producer of abundant native copper, also providing exceptional and unusual copper crystals. It extends for $200 \mathrm{~km}$, with the main economic district spreading along $40 \mathrm{~km}$, and up to $4 \mathrm{~km}$ wide (see Bornhorst and Mathur, 2017, for details). The deposit was an important source used by Native
Americans in order to make a variety of tools that were traded all across North America, since 3000 BCE (e.g., Cleland, 1992). The Keweenaw Peninsula became a prospector rush in 1843, beginning with the town of Copper Harbor, first accessible only by sea. The area grew into an industrial copper (and silver) deposit, with sometimes tons of pure copper being unearthed. It remained active, mainly until the early 20th century, and stopped with its last active mine, White Pine, which closed in 1996 (e.g., Weege and Pollack, 1971; Krause, 1992; Lankton, 2010). Nowadays, the area does not live off of the mining activity any longer, even if there is a new prospect at Copperwood, in Gogebic County, located in the Upper Peninsula of Michigan. However, there are 
some actively preserved historical mining sites such as the renowned Quincy Mining Company Hoist and Shaft Rock Houses. The Keweenaw National Historical Park is nowadays a thriving touristic area, with prosperous towns such as Hancock and Houghton and the Michigan Technological University (the former Michigan Mining School created in 1885).

Copper is also a highly collectable natural mineral: its unique patina and metallic luster combined with its diverse crystallization make it a must-have for private and public mineral collections. Among the various deposits around the world of aesthetic natural copper minerals, the Michigan Copper Country is of particular importance. First, this extensive deposit provided the mineral collecting market with a great number of outstanding copper crystals, occupying a prominent place in every fine mineralogical museum (Fig. 1). Second and most importantly, astonishing copper crystals were unearthed: they exhibit unusual and still unexplained habits (Fig. 2).

In addition to their sizes and aesthetic qualities, these crystals exhibit a high percentage of anomalous curious crystallographic shapes that have intrigued mineralogists and crystallographers. Most crystals show complex tetrahexahedral shapes (Fig. 2), which are unusual compared to other copper crystals from other localities and do not agree with simple crystallographic models for pure native copper. In this study, our attention is turned towards these unexpected crystals from the Michigan Copper District.

This paper is in the lineage of research conducted on (sometimes highly valued) natural metal specimens from museums' collections, such as gold and silver wires, in order to better understand their crystallization process (e.g., Tresmin et al., 2017; Böllinghaus et al., 2018; Anderson et al., 2019). This has been made possible thanks to naturalist observations coupled with analyses performed with state-ofthe-art instruments and the will of museums to open their entire collection, even the most valuable part, to research.

\section{Crystallography of Michigan copper crystals: an old famous unsolved question}

The first detailed study on Michigan copper crystals was published by Dana in 1886 (Dana, 1886). This author reported five $\{h k 0\}$ tetrahexahedral forms: $\{410\},\{310\},\{210\},\{520\}$, and $\{530\}$. A tetrahexahedron, also named tetrakis hexahedron, is a Catalan solid with 24 faces (Catalan, 1895); each face is an isosceles triangle, and the faces form pyramids, the bases of which are the $\{100\}$ square faces of a cube (Fig. 3). The $\{410\}$ form is the most common, followed by that of $\{210\}$ and $\{530\}$. Complete $\{410\}$ tetrahexahedrons are acknowledged (Fig. 2). The $\{311\}$ and $\{211\}$ faces of the tetragonotrioctahedron, also commonly named trapezohedron or deltoidal icositetrahedron, another Catalan solid, are less common. This shape may be described as a polyhe- dron with 24 tetragonal faces, each face being a kite (deltoid). These last-mentioned faces do not usually give complete shapes but rather small faces modifying the most common dominant shapes.

Later, Wilson and Dyl (1992) performed an examination of copper crystals throughout the district. With a contact goniometer, they analyzed small crystals (4 mm or less in diameter) in close association with prehnite and often with quartz and calcite. They concluded that there does not appear to be any relationship between crystal shape and the locality or lode of origin within the district and that a significant percentage of copper crystals with identifiable forms proved to be $\{750\}$ tetrahexahedrons.

These studies have also concluded that the $\{110\}$ dodecahedrons are uncommon. This form mainly occurs as small crystals ( $2 \mathrm{~mm}$ or less). It is often modified by other faces, but complete dodecahedrons do sometimes occur. The $\{100\}$ cube is often modified by tetrahexahedral faces. The $\{111\}$ octahedron is the rarest of the simple forms and is extremely rare as an unmodified form or as a spinel $(\Sigma 3)$ twin.

The frequency of the tetrahexahedral crystal shapes of the Michigan copper crystals is anomalous for at least two reasons. The first one is empirical. In a great majority of the crystals from other deposits, the faces that occur the most do not exhibit frequent (410), (530), and (750) tetrahedral faces (Dana, 1886; Goldschmidt, 1918; Hintze, 1904). In other worldwide copper deposits, crystals with $\{100\}$ cubic and $\{110\}$ dodecahedral shapes are quite common. The $\{111\}$ faces are also common but do not systematically give octahedrons: they often appear as the very common spinel $(\Sigma 3)$ twin, with a flattened triangular shape, which results from the $\{111\}$ composition (contact) plane. Crystals with prominent tetrahexahedral faces are otherwise very rare. Goldschmidt has mentioned only one case from Naalsoe (Faroe Islands), the most common shape in this deposit remaining a common octahedron (Goldschmidt, 1918). The $\{210\}$ and $\{520\}$ faces are less rare and appear as secondary faces in a significant number of places (Hintze, 1904).

The second reason for which the frequency of the tetrahexahedral crystal shapes of the Michigan copper crystals is anomalous is both theoretical and experimental. As far as we know, the complex tetrahexahedral and tetragonotrioctahedral faces in a pure copper equilibrium crystal shape (ECS), without any surface contaminant, are not theoretically predicted by any crystallographic and/or thermodynamic crystal shape theory and have not been experimentally studied (see Sect. 3 below). In order to understand the origin of anomalous faces in the Michigan copper, we reviewed the theories explaining crystal shapes and the influence of oxygen on surface structures, and we explored the oxygen content in natural crystals from selected locations using nanoscale secondary ion mass spectroscopy (NanoSIMS). We notably compared the oxygen content of natural tetrahexahedral copper from the Michigan Copper Country with other crystalline forms of copper from four other locations. 




Figure 1. Michigan copper specimen from famous French collector Colonel Vésignié, inherited by the Sorbonne mineral collection in 1954 (specimen size: $17 \times 10.5 \mathrm{~cm}$ ). This spectacular sample shows some more or less deformed $\{410\}$ tetrahexahedral crystals. Photo: Alain Jeanne-Michaud.

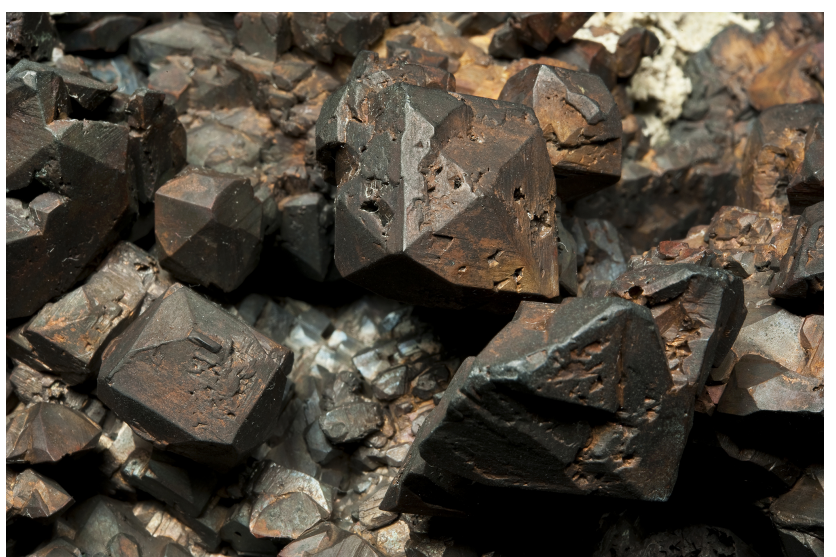

Figure 2. Close-up view of the Michigan copper sample (Sorbonne collection no. 9723). The natural $\{410\}$ tetrahexahedral copper crystals are clearly visible. Field of view: $7 \times 4.6 \mathrm{~cm}$. Photo: Alain Jeanne-Michaud.

\section{The main theories explaining crystal shapes}

To better understand why theories and models do not predict the shapes of Michigan copper crystals, let us first recall some points about faces and face stability of a crystal in equilibrium, without any contaminant. There are two main approaches: the first one is crystallographic, and the second one is more focused on thermodynamics, defects, and kinetic processes. Let us start with the crystallographic approach that is mainly being followed in this article. The starting point is that a given bulk crystal may generate an infinite number of faces; however, it has been acknowledged since the end of the 18th century that a limited number of faces usually appears. Haüy (1784) empirically established that the common faces can be described by small integer numbers, called the law of simple rational intercepts. Later, several attempts have been made in order to correlate the morphological development of crystals with their internal structure. After numerous observations and following Bravais' work (Bravais, 1851), Friedel (1904) established the Bravais-Friedel law: the observed faces on crystals are those that have the highest lattice densities; the greater the planar density, the more important 


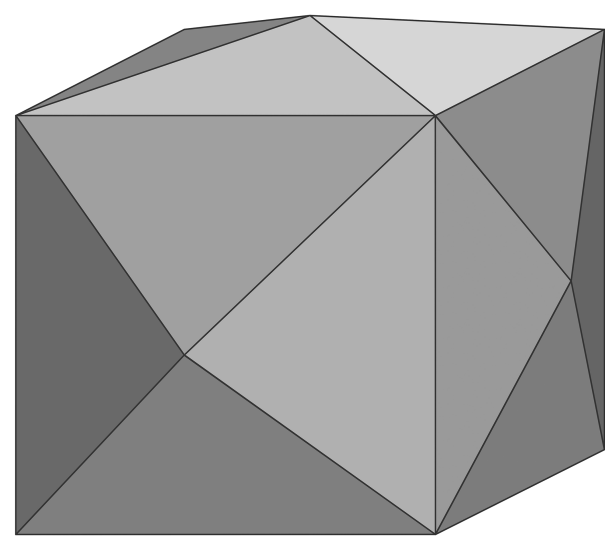

Figure 3. Drawing of a $\{410\}$ tetrahexahedral cubic crystal: each face is an isosceles triangle, and the faces form pyramids, the bases of which are the $\{100\}$ square faces of a cube.

the corresponding crystal shape. Later, Donnay and Harker (1937) extended this law by considering the screw axis and the glide mirror operations of symmetry. These laws are abbreviated as the BFDH (Bravais-Friedel-Donnay-Harker) law (Sunagawa, 2005). It statistically holds with various observations on many materials.

However some exceptions exist because these theories are purely crystallographic, and they do not include the chemical bonds. They were introduced by Hartman and Perdok (1955a, b), who concluded that the morphology of crystals is governed by chains of strong bonds, whose periods define the periodic bond chain vectors (the PBC vectors). These PBC vectors substitute the vectors of the previous theories. These $\mathrm{BFDH}$ and PBC theories remain currently the simplest basis of the morphological studies and growth process analysis (Sunagawa, 2005; Goel et al., 2019).

The second approach is related to thermodynamics and associated processes. Since the beginning of the 20th century, the theoretical equilibrium crystal shape is often deduced from the Wulff theorem (Wulff, 1901) or similarly the kinetic or velocity Wulff plot (v plot), i.e., the polar plot of the normal growth rates (Pimpinelli and Villain, 1999). The application of the theorem is the polar plot, called the $\gamma$ plot, of the surface free energy per unit surface, as a function of the crystalline orientation (Herring, 1953). This plot contains cusps associated with local minima in the surface free energy. The crystal faces are deduced from this plot with the Wulff construction: they correspond to the deepest cusps of the $\gamma$ plot.

The direct experimental determination of the free energy of solid copper is an old subject. Sundquist (1964) did it by determining the equilibrium crystal shape (ECS) of small metal crystals on an inert substrate in vacuum and by doing the Wulff construction in reverse. Back in the 1960s, the vacuum reachable in experiments was not good enough, and surface contaminations occurred. The study of ECS in ultra- high vacuum, i.e., without contaminants, started with $\mathrm{Au}, \mathrm{Pb}$, and In in the 1980s (Heyraud and Métois, 1980a, b). The ECS of copper supported on $\alpha$-alumina was determined under good ultra-high vacuum (UHV) conditions by Chatain et al. (2004). They concluded that the stable faces are (111) and (100), followed by (110) and possibly (311), which is sometimes detected.

The copper surface energy and $\gamma$ plot have been theoretically calculated using different methods (see Wang et al., 2004; Wang and Wang, 2014, and references therein). The results show that the (111) is the most stable face, followed by (100) and by (110). Other faces like (210), (310) (123), (211), and (310) have been (not systematically) investigated and in conclusion do not appear as stable faces. Thus, the thermodynamic approach does not explain the stability of complex faces on clean copper, such as the ones observed on Michigan crystals.

To complete this overview on crystal shapes, let us mention a kinetic aspect that was first taken into account by the theory developed by Burton et al. (1951), referred to as BCF. It introduced the effect of surface screw dislocation, i.e., the presence of steps, and was applied to statistical mechanisms in the treatment of surface fluctuations (Burton et al., 1951; Woodruff, 2015). This research gave rise to an approach in which the surface of an arbitrary orientation is seen as portions of flat faces called terraces, separated by steps with kinks (Williams, 1994, and references therein).

As we will see in this article, the crystallographic approach is satisfactory to explain our main observations. Let us recall that all these crystallographic theories give rise to the same conclusions. The face stability is governed by $\boldsymbol{e}_{j}$ vectors, which are either unit cell vectors in the Bravais-Friedel theory, or vectors joining special crystallographic positions (nodes or Wyckoff positions) in the Donnay-Harker theory or PBC in Hartman-Perdok theory. In many cases, as for copper, these vectors are the same whatever the model. These models also establish a hierarchy among all the possible faces of a given crystal.

The first important faces are the dense faces, which are the basic two-dimensional (2D) structures deduced from a three-dimensional (3D) crystal. The main characteristic of a dense face is that it has one unique surface site; in other words, there are no smaller identical periodicities in the unit cell (Boulliard et al., 1986; Boulliard and Sotto, 1998). In the reciprocal space, a dense face lattice is described with periodic infinite rods, which are indexed with two indices. The dense faces may be classified, following Hartman and Perdok (1955a, b), into three types:

- The F (flat) face contains two $\boldsymbol{e}_{i}$ vectors, and its structure is described by a unit symmetrical $2 \mathrm{D}$ cell with these two $\boldsymbol{e}_{i}$ vectors.

- The S (step) face contains only one $\boldsymbol{e}_{i}$ vector, and its structure is described by a unit symmetrical cell with 
one $\boldsymbol{e}_{i}$ vector, the other being $\boldsymbol{e}_{i}-\boldsymbol{e}_{j}$, with $i \neq j$, the difference between two $\boldsymbol{e}_{j}$ vectors.

- The K (kink) face contains no $\boldsymbol{e}_{i}$ vector and its structure is described by a unit symmetrical 2D cell with two $\boldsymbol{e}_{i}-$ $\boldsymbol{e}_{j}$, vectors (with $i \neq j$ ).

All other surfaces have faulted structures described as alternation of parts of dense faces (called terraces) and steps that act as faults. These less stable faces are the so-called stepterrace (ST), stepped, or vicinal faces. To be more precise, each dense face defines a domain of ST faces, with terraces that are parts of this dense face and steps characterized by a $\boldsymbol{s}_{k}$ step vector, which is the displacement from one terrace to the underlying terrace. The domain is limited by faces, which cannot be described as ST faces. Among them, there are the faces at the boundary between two dense faces. Their structure is composed of one step of the first dense face domain and one step of the second dense face domain vector, so its $2 \mathrm{D}$ cell contains a vector $\boldsymbol{s}_{k}-\boldsymbol{s}_{l}$ difference of the step vectors of each domain (Boulliard and Sotto, 1998).

A more detailed description of the ST faces belonging to a dense face domain may include the linear structure (lattice) of the steps, which is (i) dense $\mathrm{S}$ (straight line), when the distance between step atoms (or site) is one $\boldsymbol{e}_{i}$ vector; (ii) dense kinked $\mathrm{K}$ (kink), when the distance between adjacent step atoms (or site) is one $\boldsymbol{e}_{i}-\boldsymbol{e}_{j}$ vector; or (iii) SLK (straight line-kink, i.e., a broken line), a mixing of straight parts and kinks, in other orientations.

In the case of face-centered cubic copper, the $\boldsymbol{e}_{j}$ vectors are the eight vectors, parallel to $\langle 110\rangle$ directions joining two adjacent copper atoms. The most stable faces should be $\mathrm{F}$ $\{111\}$ faces, followed by the less dense $F\{100\}$ faces and finally the less stable $S\{110\}$ faces (there is no $\mathrm{K}$ face because two $\boldsymbol{e}_{i}-\boldsymbol{e}_{j}$ vectors give a (100) face). Boundary faces are, for example, $\{210\}$ between $\{100\}$ and $\{110\}$ or $\{311\}$ between $\{100\}$ and $\{111\}$.

The reciprocal space of a face that is not dense is described with periodic segments crossing the nodes of the three-dimensional reciprocal lattice of the crystal. The segments are indexed with three indices (Boulliard et al., 1986, and references therein). The surface reciprocal lattice is evidenced with various diffraction techniques: low-energy electron diffraction (LEED), reflection high-energy electron diffraction (RHEED), and grazing incidence X-ray diffraction (GIXD), for example (Duke, 1994).

As mentioned, the $\{111\},\{100\},\{110\}$ sequence of dense faces agrees, quasi-systematically, with observed faces on the native or synthetic copper crystals (Dana, 1886; Goldschmidt, 1918; Hintze, 1904), with the exception of anomalous copper crystals from Michigan, which therefore remain unexplained by BFDH and PBC.

One way to address this anomaly is to consider that the growth process is influenced by the environment and not just by the crystallography. Influences of pressure, temperature, impurities, and their concentration (supersaturation) have been acknowledged for a long time: for example, urea in the shape of salt crystal has been known since the 18th century (Romé de L'Isle, 1783). The mechanisms of this influence are still a field of research (Aquilano et al., 2020).

\section{Surface structures and faceting}

We will see hereafter that some understanding of the anomalous shapes may be found in studies about the stability of copper faces using ultra-high vacuum (UHV) devices and techniques. It has been established for a long time that, for example, many metal dense faces exhibit new surface structures under an adsorbate (a foreign chemical species bonded upon the surface) or, more rarely, spontaneously (Duke, 1994).

It is also well known that these surface reconstructions induce quasi-systematically the faceting of the ST face: it means the surface breaks up to a so-called "hill and valley", with parts of two or more faces called facets, whose orientations are different from the initial face (Duke, 1994; Chen and Richardson, 2003; Pollinger et al., 2017). In other words, due to these new structures on dense faces, only several ST faces are stable; all other ST faces are decomposed in an alternation of parts (facets) of the dense face and parts (facets) of stable ST faces. It was shown that the structure of the stable ST faces is now characterized by a cell, which is strongly correlated to the structure of the dense face (Boulliard-Sotto law; Boulliard and Sotto, 1998). Let us consider the following: $\boldsymbol{c}_{i}$ denotes the cell (or PBC) vectors or the combination of two different cell (or PBC) vectors of the new structure upon the dense face, $s_{k}$ is the step vector associated with this dense face, and $\boldsymbol{v}_{i}$ is the set of vectors of the step atom lattice of a stable ST facet (or face). We get

$\boldsymbol{v}_{i}=n_{i} \boldsymbol{c}_{j}+m_{i} \boldsymbol{s}_{k}$.

The numbers $n_{i}$ and $m_{i}$ are integers; $m$ can be equal to 0 but is necessarily different from 0 for at least one of the cell vectors of the ST stable face structure. In that case it is usually equal to 1 , but, sometimes, it can be higher (examples with $m=2$ are known). Moreover, when $n_{i}$ does not exceed 1 for every $\boldsymbol{v}_{i}$ vector, the corresponding reciprocal lattice is characterized by infinite rods, and, consequently, the initial ST face must now be considered, in the frame of the HP model, as a dense $\mathrm{F}$ or $\mathrm{S}$ face; the $\boldsymbol{v}_{i}$ vectors act now as $\boldsymbol{e}_{i}$ vectors.

To illustrate these facts, let us consider the example of clean (100) copper face and associated ST faces, first without and then with oxygen. Without oxygen, the (100) two-dimensional (2D) lattice (Fig. 4c) is described by a square mesh whose vectors are $\boldsymbol{c}_{1}=\left(a_{0} / \sqrt{2}\right) \boldsymbol{u}_{[011]}$ and $\boldsymbol{c}_{2}=$ $\left(a_{0} / \sqrt{2}\right) \boldsymbol{u}_{[0 \overline{1} 1]}\left(a_{0}\right.$ being the fcc cubic cell parameter and $\boldsymbol{u}_{[h k l]}$ the unit vector in the $[h k l]$ direction). All the ST faces here are portions, i.e., terraces, of this (100) lattice, organized by the sublattice of the step positions. Each step is characterized by its direction and its height $\boldsymbol{s}_{k}$, here $\boldsymbol{s}_{[\overline{1} 01]}=$ 


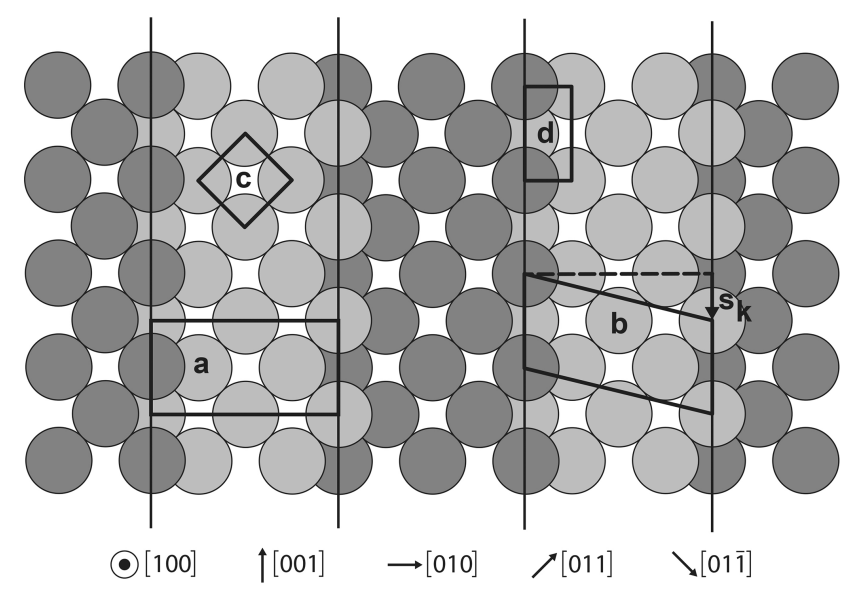

Figure 4. Schematic drawing of a copper (410) face. Label a: projection of $(2 \sqrt{2} \times \sqrt{2}) \mathrm{R} 45^{\circ}-\mathrm{O}-\mathrm{Cu}(100)$ cell; b: step atom cell, showing the relation with $(2 \sqrt{2} \times \sqrt{2}) \mathrm{R} 45^{\circ}$ cell, for which $s_{k}$ is the step vector which acts as a stacking fault; c: cell of (100) twodimensional (2D) lattice; d: step site, here equivalent to a cell of (110) 2D lattice.

$\left(a_{0} / \sqrt{2}\right) \boldsymbol{u}_{[\overline{1} 01]}$ or its symmetrical $\boldsymbol{s}_{[\overline{1} 0 \overline{1}]}$ (Fig. $\left.4 \mathrm{~b}\right)$. In the case of ( $h 10)$, the step direction is [001], which is a dense step, i.e., characterized by only one type of site, called here a "kink". Without reconstruction, each terrace may have any integer number, $n$, of [001] rows, the distance between two [001] rows being equal to $a_{0} / 2$. When $n=1$, we get the dense (110) face, whose 2D cell describes the step site (Fig. 4d).

In the case of (410) this number, $n$, is constant and equal to 4 , and the terrace width is equal to $2 a_{0} \boldsymbol{u}_{[001]}=2\left(\boldsymbol{c}_{1}-\boldsymbol{c}_{2}\right)$ (Fig. 4). The step lattice is described by a symmetrical cell whose vectors are $2 a_{0} \boldsymbol{u}_{[001]}+\boldsymbol{s}_{[\overline{1} 01]}$ and $2 \boldsymbol{a}_{0} \boldsymbol{u}_{[001]}+\boldsymbol{s}_{[\overline{1} 0 \overline{1}]}$.

Now with oxygen adsorption, the two-dimensional (100) lattice is no longer described by the $c_{1}$ and $c_{2}$ but now by the $(2 \sqrt{2} \times 2) \mathrm{R} 45^{\circ}$ cell vectors, i.e., $\left(\boldsymbol{c}_{1}+\boldsymbol{c}_{2}\right)$ and $2\left(\boldsymbol{c}_{1}-\boldsymbol{c}_{2}\right)$. The terraces are now portions of this new two-dimensional lattice. To be in agreement with this new lattice, the vectors between two first neighbor [001] steps must be $n 2\left(c_{1}-c_{2}\right)+s_{[\overline{1} 01]}$ or $2\left(c_{1}-c_{2}\right)+s_{[10 \overline{1}]}$. In the case of $n=1$, for a $\mathrm{O} / \mathrm{Cu}$ (h10)-type surface, we now get (410) with the following vector mesh (Fig. 4):

$$
\begin{aligned}
& \boldsymbol{v}_{1}=\left(\boldsymbol{c}_{1}+\boldsymbol{c}_{2}\right) \\
& \boldsymbol{v}_{2}=2\left(\boldsymbol{c}_{1}-\boldsymbol{c}_{2}\right)+\boldsymbol{s}_{[\overline{1} 01]}
\end{aligned}
$$

or

$2\left(c_{1}-c_{2}\right)+s_{[\overline{1} 0 \overline{1}]}$.

Since $n=1$, this face is dense, which is confirmed by LEED by the fact that the diffraction patterns all exhibit spots of lattice defined by $\boldsymbol{v}_{1}$ and $\boldsymbol{v}_{2}$ (Boulliard et al., 1986).

\subsection{Copper surface structures and stable faces under oxygen adsorption}

In this section, we will now consider the case of copper under oxygen adsorption, which is also summarized in Table 1. Copper dense faces undergo reconstructions for exposure to oxygen in the pressure range typically between $10^{-9}$ and $10^{-4}$ Torr. At higher pressures, around $5 \times 10^{-4}$ Torr at $350{ }^{\circ} \mathrm{C}$, for example, copper surfaces undergo oxidation with disordered islands of copper oxide (Woll et al., 1990; Lahtonen et al., 2008; Gattinoni and Michaelides, 2015).

\section{2 $\mathrm{Cu}(100)$ and associated $\mathrm{ST}$ faces}

On the (100) dense face, a more or less well-defined $(\sqrt{2} \times$ $\sqrt{2}) \mathrm{R} 45^{\circ}, \mathrm{C}(2 \times 2)$ structure appears at oxygen coverages less than or equal to $\Theta=0.25$. It is followed, at coverages less than or equal to $\Theta=0.5$, by a $(2 \sqrt{2} \times \sqrt{2}) \mathrm{R} 45^{\circ}$ structure (Boulliard et al., 1986; Woll et al., 1990; Lian et al., 2017).

Two remarkable types of ST faces arise from (100) faces of a fcc crystal. The first includes the $(h k 0)$ faces with dense $\mathrm{K}$ [001] steps, which means totally kinked steps. The step site, i.e., the cell constituted with the vector joining two first neighbor step atoms (here in the [001] direction) and the vector joining one step atom to the closest underlying terrace atom, is the cell of the (110) face (see Fig. 4). The second type includes the $(h k k)$ with dense $\mathrm{S}[01 \overline{1}]$ steps, i.e., steps without any kink. The step site here is the cell of a (111) face.

Let us consider the $(h k 0)$ faces. The stable initial $(h k 0)$ ST faces or facets, experimentally detected by LEED, are (Boulliard et al., 1986, and references therein) (410), (810), and $(12,1,0)$. Scanning tunneling microscopy (STM) studies have detected ( $4 n 10)$ nanofacets with $n$ greater than 3 (Knight et al., 1997). The ranges of stability of the $(810)$ and $(12,1,0)$ facets are small: typically, high oxygen exposure on initial ST faces is close or equal to $(810)$ and $(12,1,0)$ respectively. Moreover, these facets occur together with (410) facets.

The (410) face is stable in a wide range of oxygen exposure and has often been studied (Vlieg et al., 2002; Sheppard et al., 2010; Liu and Thiel, 2018, and references therein). The (410) structure is associated with one cell; i.e., it follows Eq. (1) with $n_{i}=1$ (Fig. 4). The reciprocal lattice, observed by LEED, for example, exhibits infinite rods: so this face has become, with the adsorbed oxygen, a dense face. The (810), (12,1,0), and $(4 n 10)$ are ST faces associated, respectively, with two, three, and $n(2 \sqrt{ } 2 \times \sqrt{ } 2) \mathrm{R} 45^{\circ}-(100)$ cells. Their step atom structures follow Eq. (1) with $n_{i}=2$, $3, \ldots, n$ respectively.

Results regarding $(h k k)$ faces are scarce. They facet into (410) and (401) facets as well as other facets, in order to maintain their orientation. These other facets are (311) for initial faces with high misorientation (from around $10^{\circ}$ ) from (100) (Trepte et al., 1967; Sotto, 1992) and (100) facets for 
initial ST faces close to (100) (Boulliard et al., 1986; Reinecke and Taglauer, 2000).

\section{3 $\mathrm{Cu}(110)$ and associated ST faces}

On the (110) dense face, a $P(2 \times 1)$ appears, followed by a $C(6 \times 2)$, under oxygen exposure similar to that giving rise to $(2 \sqrt{ } 2 \times \sqrt{ } 2) \mathrm{R} 45^{\circ}-\mathrm{O}-\mathrm{Cu}(100)$ (Coulman et al., 1991; Prévot et al., 2004, and references therein).

Two remarkable types of ST faces arise from (110) fcc crystal faces. The first includes $(h k 0)$ faces with dense $\mathrm{K}$ steps, the step being a minimum part of (100). The second type includes $(h h k)$ faces with dense $\mathrm{S}$ steps, the step being a minimum part of (111).

Let us consider the faces between (110) and (210). A (320) stable facet appears in connection with one $P(2 \times 1)-(110)$ cell, which is a dense face but with a limited range of oxygen coverage. Just before the $C(6 \times 2)-(110)$ structure appears, the (750) dense face and facets appear only on a short domain of face orientations around the (750) face. The structure of this face is connected with one $C(6 \times 2)-(110)$ cell. The (530) dense face appears after, for all ST faces between (110) and (210). The (530) dense face is connected to one $C(6 \times$ $2)-(110)$ cell with a double step height (Boulliard et al., 1986).

The (210) face is the boundary face between (100) and (110) associated ST faces. It could be stable (McKee et al., 1978) but with a structure described by the alternation of (410) and (530) terraces, i.e., a nanofaceting. At high oxygen exposure conditions, faceting in (410) and (530) facets occurs (Trepte et al., 1967; Legrand-Bonnyns and Ponslet, 1975).

\section{4 $\mathrm{Cu}(111)$ and associated ST faces}

Initially, no structure was detected on $\mathrm{Cu}(111)$ faces, and it was believed that oxygen atoms were disordered, due to the higher density of copper atoms at the surface (Niehus, 1983). Later, structures with large unit cells, 29 to 44 times larger than the clean copper (111) cell, were detected by means of STM (scanning tunneling microscopy) and HEIS (highenergy ion scattering) (Jensen et al., 1992).

Two remarkable types of ST faces arise from (111) fcc crystal faces. The first includes $(h h k)$ faces with dense $\mathrm{K}$ steps, the step site being a (110) cell. The second type includes ( $h k k$ ) faces with dense S steps, the step site being a (100) cell.

The stability of the (322), which has (111) terraces, is not well established: for some authors it is stable (Trepte et al., 1967; Milne, 1982), yet for others it is not (Baetzold, 1980). The (311) face, which is the boundary between ST ( $h k k$ ) faces with (100) terraces and those with (111) terraces, is stable (Trepte et al., 1967; Baetzold, 1980; Milne, 1982; Sotto, 1992). Adsorption of oxygen upon (211) induces a step doubling (Liu and Thiel, 2018). The (hhk) faces facet into dense (110) facets, with $\mathrm{C}(6 \times 2)-\mathrm{O}$ structure, and (111) facets (Trepte et al., 1967).

\subsection{Summary and first conclusions}

One can readily observe that the comparison between the stable copper faces or facets after oxygen exposure in a UHV experimental setup, and the stable faces of the Michigan crystals show remarkable similarities (Table 1). The most common faces reported by Dana, i.e., (410), (210), and (530), and the less common (750) and (311), are stable faces under oxygen adsorption at pressure-temperature conditions lower than those that result in three-dimensional oxidation.

Some discrepancies, however, do exist. The (520) natural faces have not yet been detected during oxygen exposure, but this face is rare. The (810), (12,1,0), (320), and (322) faces observed during UHV experiments have not been observed in natural crystals, but they are either doubtful (it is the case for (322)) or have small ranges of stability (which is the case for (810), (12,1,0), and (320)). Therefore, the discrepancies do not seem to be important as no important stable face is involved.

If we consider that the anomalous shapes of Michigan copper crystals are due to oxygen, it would then imply that crystals with "normal" shapes were not exposed to the same amounts of oxygen or may be not exposed to oxygen at all. Consequently, the amount of oxygen impurity in copper should be lower in crystals with normal shapes than in Michigan crystals with anomalous shapes. In order to evaluate the oxygen contents in a range of natural copper crystals, and to establish how they compare with that of tetrahexahedral crystals from Michigan, we performed oxygen dosing on several crystals from five different localities.

\section{Dosing oxygen content by NanoSIMS}

\subsection{Methodology and data reduction}

Oxygen concentrations were measured in scanning imaging mode using the NanoSIMS 50 at IMPMC, Paris, France. The samples were mounted as sections polished with a $1 \mu \mathrm{m}$ diamond paste, using only ethanol to prevent oxidation. $\mathrm{A} \sim 5 \mathrm{~min}$ sputter cleaning of the sample over a $15 \mu \mathrm{m} \times 15 \mu \mathrm{m}$ area with a $2 \mathrm{nA} \mathrm{Cs}^{+}$beam was conducted, aiming at removing surface oxidation and contamination on the one hand and at achieving sputtering equilibrium (hereafter "presputtering") on the other hand. Images were acquired after this cleaning process, using a $\mathrm{Cs}^{+}$beam of $0.5 \mathrm{pA}(\sim 100 \mathrm{~nm})$ rastered over $10 \times 10 \mu \mathrm{m}$ with a dwell time of $300 \mu \mathrm{s} /$ pixel. Each acquisition consists of 15 image planes of $256 \times 256$ pixels. ${ }^{12} \mathrm{C}^{-},{ }^{16} \mathrm{O}^{-},{ }^{63} \mathrm{Cu}^{-}$, and ${ }^{63} \mathrm{Cu}^{16} \mathrm{O}^{-}$ions were collected simultaneously on four electron multipliers. ${ }^{12} \mathrm{C}^{-}$was used to monitor the presence of polishing diamonds incrusted in soft $\mathrm{Cu}$. $\mathrm{O}$ concentrations in $\mathrm{Cu}$ were determined using two methods, using either the $\mathrm{O}^{-} / \mathrm{Cu}^{-}$ra- 
Table 1. Stable faces of Michigan copper crystals and stable high indices faces or facets under oxygen adsorption.

\begin{tabular}{llll}
\hline Faces indices & Michigan copper crystal & Stable facets under chemisorbed oxygen & Related oxygen structure upon dense face \\
\hline$(410)$ & yes, common & yes, stable in a large range & $(2 \sqrt{2} \times \sqrt{2}) \mathrm{R} 45^{\circ} /(100)$ \\
$(810)$ & no & yes, in a limited range & $(2 \sqrt{2} \times \sqrt{2}) \mathrm{R} 45^{\circ} /(100)$ \\
$(12,1,0)$ & no & yes, in a limited range & $(2 \sqrt{2} \times \sqrt{2}) \mathrm{R} 45^{\circ} /(100)$ \\
$(210)$ & yes, less common & yes, "nanofaceted" & boundary $(100)-(110)$ \\
$(750)$ & yes, common & yes, in a short range of coverage & $\mathrm{C}(6 \times 2) /(110)$ \\
$(320)$ & no & yes, stable at low coverage & $\mathrm{P}(2 \times 1) /(110)$ \\
$(530)$ & yes, less common & yes, stable in a large range & $\mathrm{C}(6 \times 2) /(110)$ \\
$(520)$ & yes, less common & no & - \\
$(311)$ & yes, rare & yes, stable in a large range & boundary $(100)-(111)$ \\
$(211)$ & yes, rare & yes (step doubling) & - \\
$(322)$ & no & doubtful stability & - \\
\hline
\end{tabular}

tio or the $\mathrm{CuO}^{-} / \mathrm{Cu}^{-}$ratio normalized to those of an OFHC (UNS C10100) sample of maximum nominal concentration of 5 ppm (Günter, 1999), measured at the beginning and at the end of the analytical session.

Additional measurements of a natural cuprite $\left(\mathrm{Cu}_{2} \mathrm{O}\right)$ sample from Mashamba West Mine (Democratic Republic of Congo) from the collection of the Sorbonne University demonstrated that the relative sensitivity factors between the measured ratios and the true ratios are different between cuprite and $\mathrm{Cu}$ metal and that the emission of $\mathrm{O}$ is strongly enhanced in cuprite. The $\mathrm{O}$ concentrations in $\mathrm{Cu}$ metal determined using the $\mathrm{O}^{-} / \mathrm{Cu}^{-}$and the $\mathrm{CuO}^{-} / \mathrm{Cu}^{-}$ratios are comparable for low concentrations but differ significantly for high concentrations (linear relationship of slope 0.64). This relationship is different for $\mathrm{Cu}_{2} \mathrm{O}$ (slope $\sim 2$ ), allowing analyses with significant oxide contributions to be discarded. The $\mathrm{C}$ map showed incrustation of polishing diamonds in several samples. These diamonds were partially to totally eroded during presputtering, leaving $\sim 1 \mu \mathrm{m}$ areas with higher $\mathrm{O}$ contents due to protection from presputtering. These areas were removed by masking during image processing. Image processing further demonstrated that the intra-image heterogeneity is comparable to the inter-image reproducibility in most samples and is on the order of $10 \%-20 \%$, which can be attributed to sample heterogeneity rather than uncertainty on the analyses, in agreement with the fact that two samples have significantly lower dispersion. The reported uncertainty on individual analyses is the quadratic sum of the precision due to counting statistics on each image and the reproducibility on the OFHC standard calculated as the standard error of the mean to avoid overestimation due to heterogeneity and corresponds to a $95 \%$ confidence interval.

\subsection{The samples}

Six samples were analyzed (Table 2). The first one is OFHC copper, a piece of UHV gasket. The five following samples were collected from specimens of the Collection des Minéraux of the Institut de Minéralogie, Physique des
Matériaux et Cosmochimie (IMPMC), four of which exhibiting well-formed crystals. The first one (referred to in the museum file under no. 9723) comes from the Michigan Copper District (USA) with the typical more or less deformed $\{410\}$ tetrahexahedral shape (Figs. 1,2); this specimen comes from the worldwide recognized collection of Colonel Vésignié, donated to the Sorbonne collection in 1954. The second one (no. 3770) is from Bisbee (Arizona, USA); it shows crystals which are cubes modified by small $\{110\}$ dodecahedron faces. The third one (no. 11322) is from Ray, Arizona (USA); the crystals have the flat $\Sigma 3$ spinel twin shape, i.e., with two well-developed parallel triangular (111) faces. The fourth (no. 2901) is from Corocoro (Pacajes, Bolivia); its copper shape is dendritic with poorly defined spinel twins, the copper being a little altered by malachite. The fifth (no. 12518) is from Redruth (Cornwall, UK); the crystal shapes exhibit $\{100\},\{110\}$, and $\{111\}$ faces. There are also several wires elongated along the [111] axis, and it is associated with post-grown cuprite.

\subsection{Results}

Overall, the oxygen concentrations on natural copper specimens obtained by NanoSIMS range between $\sim 3$ and $11 \mathrm{ppm}$ $\mathrm{O}$ and are comparable in magnitude to that in the OFHC copper (Table 3). The Michigan copper sample contains the highest concentration in $\mathrm{O}$, ranging between $\sim 7.7$ and $\sim 11 \mathrm{ppm}$, with an average at $\sim 9 \mathrm{ppm}$. Other samples have O concentrations comparable to or lower than that in the OFHC copper. Corocoro and Ray copper crystals are very homogenous, with average concentrations of $\sim 5 \pm 0.5 \mathrm{ppm}$ and $\sim 4 \pm 0.4 \mathrm{ppm}$ ( 2 standard deviations), respectively. Bisbee copper has the second highest, up to $7.1 \mathrm{ppm}$, with an average at $\sim 6.5 \mathrm{ppm}$. We acknowledge that the concentrations in $\mathrm{O}$ in all samples are low, but they are well above 2 standard deviations, and different samples have different average concentrations and different levels of heterogeneity, testifying to real differences. The lowest concentration in Redruth copper at $\sim 3.2 \pm 0.5 \mathrm{ppm}$ sets an upper limit for surface contami- 
Table 2. List of the samples analyzed by NanoSIMS.

\begin{tabular}{lll}
\hline $\begin{array}{l}\text { Copper (Sorbonne } \\
\text { catalog number) }\end{array}$ & Locality & Characteristics \\
\hline OFHC & $/$ & UHV gasket fragment. \\
no. 9723 & Michigan (USA) & Typical more or less deformed $\{410\}$ tetrahexahedral crystals. \\
no. 3770 & Bisbee (Arizona, USA) & Cubes modified by small $\{110\}$ dodecahedron faces. \\
no. 11322 & Ray, Arizona (USA) & Flat $\Sigma 3$ spinel twin shape \\
no. 2901 & Corocoro (Pacajes, Bolivia) & Dendritic with poorly defined spinel twins. \\
no. 12518 & Redruth, Cornwall (UK) & With $\{100\},\{110\}$, and $\{111\}$ faces and several wires elongated \\
& & along the $[111]$ axis. \\
\hline
\end{tabular}

nation, which has to be lower than 3 to $3.5 \mathrm{ppm}$. The lowest concentrations measured in Michigan copper overlap the highest concentrations measured in Bisbee copper. Although only five analyses were conducted per sample, the weighted means in the two samples are already distinct by more than 2 standard errors of the means $(8.97 \pm 0.68$ and $6.39 \pm 0.48 \mathrm{ppm}$ for Michigan and Bisbee copper, respectively, determined using the $\mathrm{O} / \mathrm{Cu}$ ratio; $7.59 \pm 0.57$ and $5.27 \pm 0.40 \mathrm{ppm}$, respectively, using the $\mathrm{CuO} / \mathrm{Cu}$ ratio, where uncertainties are 2 standard errors of the mean). Hence, the average $\mathrm{O}$ concentration in the Michigan copper specimen can be considered significantly higher than that of all other samples, with a confidence interval of at least $95 \%$. These higher oxygen concentrations in the Michigan copper sample are in line with the influence of oxygen as the trigger to the growth of anomalous tetrahexahedral faces. We acknowledge that these data present preliminary results and that a larger sampling would be valuable, but this would be beyond the scope of this study.

\section{Discussion}

The above results demonstrated that stable facets observed after oxygen adsorption in a UHV chamber can be the same as anomalous faces found in natural copper crystals. This observation raises some questions. The first one is about explaining how the faceting phenomenon and growth process are connected. The answer to that question is not unique and may involve many topics, such as step free energies, relative growth rates, Wulff plots, and surface diffusion (Jeong and Williams, 1999; Pimpinelli and Villain, 1999; Bellman et al., 2017). Let us first consider the growth process. It has been demonstrated that the growth of single crystal with welldefined faces is often due to the spiral growth mechanism in which steps are implied. The steps, especially in a metal like copper, are generated by the emergence of screw dislocations on a dense face. These steps often facet in such a way that their directions are dense, i.e., with only one step site, which gives rise to a polygonal spiral step. The step sites are preferential adsorption sites, so that during crystal growth, matter is fixed on the step edge, and as a consequence, the steps move, and the crystal grows (Verma, 1953; Sunagawa, 2005;
Dekeyser and Amelincks, 1955). Within this basic step-flow mechanism, a step ceases to move when it reaches the corner with another dense face. When there is a surface reconstruction, the dense face can now be a new (step-terrace) dense face related to the surface reconstruction. In other words, the steps are stabilized when the orientation and distances between them agree with the surface structure (i.e., satisfies Eq. 1). Therefore, (dense) ST faces can grow when the surface reconstruction occurs.

This growth mechanism might also explain why the dense (100), (110), and (111) faces are rare in copper crystals that undergo oxygen-induced reconstruction. Let us consider, for example, a hypothetical initial flat (100) face. With $(2 \sqrt{ } 2 \times \sqrt{ } 2) \mathrm{R} 45^{\circ}$ oxygen structure, the stable step directions are $\langle 100\rangle$ (Boulliard et al., 1986): the steps move perpendicular to these directions, and since the number of steps that are induced by the screw dislocations increases with the crystal growth on this (100) initial face, it implies the growth of (410), (410), (401), and (401) facets. Considering the other symmetrically equivalent initial $\{100\}$ faces of the cube, the formation of $\{410\}$ pyramids on each cube face leads to a tetrahexahedral shape. A similar explanation works for (110) with steps parallel to $\langle 100\rangle$. In the case of (111), the oxygen structure is poorly defined; there is no reconstruction that stabilizes PBC or equivalent vectors: the face might be seen here as a $\mathrm{K}$ face, which grows faster and disappears (Sunagawa, 2005).

Let us now consider the faceting mechanism. As we previously discussed, reconstruction on a dense face implies the stability for some complex faces. On other faces, the structure can be seen as highly faulted by steps, which do not fit with the new periodicities of the $\mathrm{O} / \mathrm{Cu}$ reconstruction. This discrepancy can create stress. The steps move until they are reorganized in stable facets: this step bunching leaves dense faces and stable ST facets. This self-ordering process is based, as in the growth process, on the moving of the steps. However, there is a difference. In faceting, there is a step bunching on a preexisting face. In crystal growth, there is a step flow: in a first stage, the steps might be distant and then move with adsorption of matter until a stable ST face is reached (Jeong and Williams, 1999; Bellman et al., 2017). 
Table 3. Oxygen concentration in copper.

\begin{tabular}{|c|c|c|c|c|}
\hline & \multicolumn{2}{|c|}{$\mathrm{O}(\mathrm{ppm})$} & \multicolumn{2}{|c|}{$\mathrm{O}(\mathrm{ppm})$} \\
\hline & $(\mathrm{O} / \mathrm{Cu})$ & $2 \sigma$ & $(\mathrm{CuO} / \mathrm{Cu})$ & $2 \sigma$ \\
\hline OFHC 1 & 4.4 & 0.7 & 4.5 & 0.7 \\
\hline OFHC 2 & 4.7 & 0.8 & 5.3 & 0.7 \\
\hline OFHC 3 & 6.1 & 1.0 & 6.0 & 0.9 \\
\hline OFHC 4 & 5.8 & 1.0 & 5.2 & 0.9 \\
\hline OFHC 5 & 5.8 & 1.0 & 5.3 & 0.9 \\
\hline OFHC end 1 & 3.8 & 0.6 & 4.5 & 0.7 \\
\hline OFHC end 2 & 4.4 & 0.7 & 4.2 & 0.7 \\
\hline $\operatorname{avg} \pm 2 S D$ & 5.0 & 1.8 & 5.0 & 1.3 \\
\hline Michigan 1 & 9.5 & 1.6 & 6.9 & 1.2 \\
\hline Michigan 2 & 7.8 & 1.3 & 7.2 & 1.2 \\
\hline Michigan 3 & 8.5 & 1.4 & 7.0 & 1.2 \\
\hline Michigan 4 & 10.8 & 1.8 & 8.9 & 1.5 \\
\hline Michigan 5 & 9.4 & 1.6 & 8.7 & 1.4 \\
\hline avg $\pm 2 S D$ & 9.2 & 2.3 & 7.8 & 1.9 \\
\hline Bisbee 1 & 6.5 & 1.1 & 6.0 & 1.0 \\
\hline Bisbee 2 & 7.1 & 1.2 & 5.0 & 0.9 \\
\hline Bisbee 3 & 6.7 & 1.1 & 5.4 & 0.9 \\
\hline Bisbee 4 & 6.7 & 1.1 & 5.4 & 0.9 \\
\hline Bisbee 5 & 5.5 & 0.9 & 4.8 & 0.8 \\
\hline $\operatorname{avg} \pm 2 \mathrm{SD}$ & 6.5 & 1.2 & 5.3 & 0.9 \\
\hline Ray 1 & 4.1 & 0.7 & 4.3 & 0.7 \\
\hline Ray 2 & 3.9 & 0.6 & 4.2 & 0.7 \\
\hline Ray 3 & 3.7 & 0.6 & 4.1 & 0.7 \\
\hline Ray 4 & 3.8 & 0.6 & 4.3 & 0.7 \\
\hline Ray 5 & 4.0 & 0.7 & 4.1 & 0.7 \\
\hline $\operatorname{avg} \pm 2 S D$ & 3.9 & 0.3 & 4.2 & 0.2 \\
\hline Corocoro1 & 5.5 & 0.9 & 5.0 & 0.8 \\
\hline Corocoro 2 & 4.8 & 0.8 & 4.7 & 0.8 \\
\hline Corocoro 3 & 5.1 & 0.9 & 4.7 & 0.8 \\
\hline Corocoro 4 & 4.8 & 0.8 & 4.4 & 0.8 \\
\hline Corocoro 5 & 4.7 & 0.8 & 4.5 & 0.8 \\
\hline $\operatorname{avg} \pm 2 \mathrm{SD}$ & 5.0 & 0.6 & 4.7 & 0.4 \\
\hline Redruth 1 & 3.7 & 0.6 & 4.0 & 0.7 \\
\hline Redruth 2 & 3.2 & 0.5 & 4.2 & 0.6 \\
\hline Redruth 3 & 3.4 & 0.6 & 3.7 & 0.6 \\
\hline Redruth 4 & 3.4 & 0.6 & 3.3 & 0.5 \\
\hline Redruth 5 & 5.3 & 0.9 & 4.5 & 0.8 \\
\hline $\operatorname{avg} \pm 2 \mathrm{SD}$ & 3.8 & 1.7 & 3.9 & 0.9 \\
\hline
\end{tabular}

This difference may explain why the $(810),(12,1,0)$, and ( $4 n 10)$ have not been detected on natural Michigan copper crystals. These faces are only stable at higher oxygen exposure in the UHV chamber (Boulliard et al., 1986). For lower ones, they facet into (410) and (100) facets. It means that they are stable only when the diffusion process involved in the faceting is stopped by a quick settlement of the oxygen- induced structure. In other words, these faces are less stable than (410) but more stable than other $(h 10)$ faces, with $h \neq 4 n$, which does not agree with $(2 \sqrt{ } 2 \times \sqrt{ } 2) \mathrm{R} 45^{\circ}-\mathrm{O}$ $\mathrm{Cu}(100)$. In the case of crystal growth, the inflow of matter destabilizes these $(4 n 10)$ faces, and the more stable (410) face remains.

The presence of oxygen in the Michigan copper occurrence is well attested. A thin coating of copper oxide (cuprite and/or tenorite) is observed on the copper crystals: this coating has a pre-mining origin and is prevalent throughout the district (Wilson and Dyl, 1992). Here we showed a slightly higher oxygen concentration within the Michigan copper crystals compared to copper from other localities. In the Michigan copper crystal sample analyzed, the $\mathrm{O}$ content has an average value at $\sim 9 \mathrm{ppm}$, i.e., 1.5 to 2 times higher than that of other samples that have an average $\mathrm{O}$ content between $\sim 4$ and $6.5 \mathrm{ppm}$ (as in OFHC copper; see Table 3). Oxidizing conditions might have existed in the Michigan district, at least during the final stages of mineralization. Wilson and Dyl (1992) suggested that the presence of oxygen just below oxidizing conditions, during crystal growth, results from ore solution mixing with meteoric waters. Let us remark here that the $\mathrm{O}$-adsorbed copper surfaces are remarkably stable during a long-term growth process: it can be explained by the fact that the $\mathrm{O}-\mathrm{Cu}$ surfaces are passivated, and therefore there are no more dangling bonds. Moreover, surface oxygen atoms do not seem to be easy to incorporate into the growing copper crystal. Indeed, despite the fact that the amount of oxygen in the Michigan copper with anomalous faces is higher than in copper of other locations, it remains low, not being higher than $11 \mathrm{ppm}$.

\section{Conclusion}

Natural copper crystals from the Michigan mines in the Keweenaw Peninsula exhibit unusual faces, with tetrahexahedral habits. The anomalous faces cannot be explained by the usual crystal growth theories involving the internal copper crystal structure alone. UHV surface studies have shown that crystalline surfaces undergo reconstruction, rarely spontaneously but frequently under oxygen adsorption. Additional studies have shown that these reconstructions involve the stability of complex step and terrace (ST) faces. It appears that most anomalous faces of Michigan copper crystals have similar stable faces or facets than those exhibited under oxygen adsorption. These observations and deductions prompted us to postulate that the anomalous shapes of the Michigan copper crystals could be due to the presence of oxygen during the growth process. In order to test this theory, NanoSIMS analyses of $\mathrm{O}$ content in natural copper from the Michigan district and four other locations were conducted. They showed that the oxygen content of Michigan copper is low but on average about 1.5 to 2 times higher than that of other copper crystals. Considering the fact that the oxygen reconstructions associ- 
ated with the complex faces are stable just before oxidation, this result supports our model and suggests that Michigan copper crystals grew in quite a rare stable range of oxygen partial pressure and temperature close to the oxidation state, higher than the "usual" growth conditions occurring in the other copper deposits. An extensive study of copper crystals from different locations within the Michigan district and with different crystallographic habits is now required to confirm with certainty the validity and details of our model and to fully understand the redox conditions that prevailed in the Michigan district. These results also suggest that UHV experiments of adsorption upon metal surfaces could be of great help in acquiring a crystallographic control on the growth of crystals and nanocrystals, which is of premier importance in shape-dependent catalysis and sensor properties, currently intense and challenging fields of research (e.g., Niu and $\mathrm{Xu}$, 2011).

Data availability. NanoSIMS raw image data used in the present work are available publicly on the ZENODO repository (https://doi.org/10.5281/zenodo.4462260; Boulliard et al., 2021).

Author contributions. JCB is the main investigator of this work, alongside EG. JCB and JA designed the NanoSIMS experiments, and JA carried them out. EG handled the manuscript along with $\mathrm{JCB}$, as well as the review and the editing processes, with contributions from all co-authors.

Competing interests. The authors declare that they have no conflict of interest.

Acknowledgements. The authors would like to thank Alain JeanneMichaud for the pictures and drawings, as well as Rémi Duhamel, who helped with the NanoSIMS analyses. We are also grateful to the two anonymous referees, who helped improve the manuscript greatly, and to the editors for their time and help through the review process. The authors are also grateful to the Société Française de Minéralogie et Cristallographie (SFMC) for supporting the publication of this paper.

Review statement. This paper was edited by Luca Bindi and reviewed by two anonymous referees.

\section{References}

Anderson, C. J., Mathur, R., Rakovan, J., and Tremsin, A. S.: Natural solid-state ion conduction induces metal isotope fractionation, Geology, 47, 1-5, https://doi.org/10.1130/G45999.1, 2019.

Aquilano, D., Bruno, M., and Pastero, L.: Impurity effects on habit change and polymorphic transitions in the system: aragonite-calcite-vaterite, Cryst. Growth Des., 20, 1334-1341, https://doi.org/10.1021/acs.cgd.9b01651, 2020.

Baetzold, R. C.: Study of the chemisorption on copper low-index and stepped surfaces, Surf. Sci., 95, 286-298, https://doi.org/10.1016/0039-6028(80)90142-9, 1980.

Bellman, K., Pohl, U. W., Kuhn C., Wernicke T., and Kneissl, M.: Controlling the morphology transition between step-flow growth and step-bunching growth, J. Cryst. Growth, 478, 187192, https://doi.org/10.1016/j.jcrysgro.2017.09.007, 2017.

Böllinghaus, T., Lüders, V., and Nolze, G.: Microstructural insights into natural silver wires, Sci. Rep.-UK, 8, 9053, https://doi.org/10.1038/s41598-018-27159-w, 2018.

Bornhorst, T. J. and Mathur, R.: Copper Isotope Constraints on the Genesis of the Keweenaw Peninsula Native Copper District, Michigan, USA, Minerals, 7, 185, https://doi.org/10.3390/min7100185, 2017.

Boulliard, J. C. and Sotto, M. P.: On the relations between the surface structures and the stability of complex faces, Surf. Sci., 414, 131-147, https://doi.org/10.1016/S0039-6028(98)00503-2, 1998.

Boulliard, J. C., Domange, J. L., and Sotto, M. P.: Structural changes of vicinal copper surfaces induced by oxygen adsorption, Surf. Sci., 165, 434-446, https://doi.org/10.1016/00396028(86)90818-6, 1986.

Boulliard, J.-C., Aléon, J., and Gaillou, E.: On the anomalous shapes of native copper crystals from the Michigan Copper Country, Zenodo, https://doi.org/10.5281/zenodo.4462260, 2021.

Bravais, A.: Etudes cristallographiques, Journal de l'Ecole Polytechnique, XXXIV, 101-276, 1851.

Burton, W. K., Cabrera, N., and Franck, F. C.: The growth of crystals and the equilibrium structure of their surfaces, Philos. T R. Soc. A, 243, 299-358, https://doi.org/10.1098/rsta.1951.0006, 1951.

Catalan, E.: Mémoire sur la théorie des polyèdres, J. École Polytechnique, 41, 1-71, 1895.

Chatain, D., Ghetta, V., and Wynblatt, P.: Equilibrium shape of copper crystals grown on sapphire, Interface Sci., 12, 7-18, https://doi.org/10.1023/B:INTS.0000012290.07441.a8, 2004.

Chen, Q. and Richardson, N. V.: Surface faceting induced by adsorbates, Prog. Surf. Sci., 73, 59-77, https://doi.org/10.1016/j.progsurf.2003.09.002, 2003.

Cleland, C. E.: Rites of Conquest: The History and Culture of Michigan's Native Americans, University of Michigan Regional Editor, 360 p., https://doi.org/10.3998/mpub.9272, 1992.

Coulman, D., Wintterlin, J., Barth, J. V., Ertl, G., and Behm, R. J.: An STM investigation of the $\mathrm{Cu}(110)-\mathrm{C}(6 \times 2) \mathrm{O}$ system, Surf. Sci., 240, 151-162, https://doi.org/10.1016/00396028(90)90738-T, 1990.

Dana, E. S.: On the crystallization of the native copper, Am. J. Sci., 32, 413-429, 1886.

Dekeyser, W. and Amelincks, S.: Les dislocations et la croissance des cristaux, Dunod, Paris, 1955.

Donnay, J. D. H. and Harker, D.: A new law of crystal morphology extending the law of Bravais, Am. Min., 22, 446-467, 1937.

Duke, C. B.: Surface Science: The First Thirty Years, Duke, North Holland, https://doi.org/10.1016/0039-6028(94)90678-5, 1994.

Friedel, G.: Sur la loi de Bravais considérée comme loi d'observation, C. R. Acad. Sc., 139, 221-226, 1904. 
Gattinoni, C. and Michaelides, A.: Atomistic details of oxide surfaces and surface oxidation: the example of copper and its oxides, Surf. Sci. Rep., 70, 424-447, https://doi.org/10.1016/j.surfrep.2015.07.001, 2015.

Goel, S., Sinha, N., Yadah, H., and Kumar, B.: On the prediction of external shape of $\mathrm{ZnO}$ nanocrystals, Physica E Low Dimens. Syst. Nanostruct., 106, 291-297, https://doi.org/10.1016/j.physe.2018.08.014, 2019.

Goldschmidt, V.: Atlas des Krystallformen; band v, Carls Winters, Heidelberg, 1918.

Günter, J.: Copper: its trade, manufacture, use, and environmental status, edited by: Kunding, K. J. A., ASM International, Materials Park, Ohio, 1999.

Hartman, P. and Perdok, W. G.: On the relations between structure and morphology of crystal I., Acta Cryst., 8, 49-52, https://doi.org/10.1107/S0365110X55000121, 1955a.

Hartman, P. and Perdok, W. G.: On the relations between structure and morphology of crystal I., Acta Cryst., 8, 521-524, https://doi.org/10.1107/S0365110X55001679, 1955b.

Haüy, R.-J.: Essai d'une théorie sur la structure des crystaux, Gogué \& Née de la Rochelle, Paris, 1784.

Herring, C.: The use of classical macroscopic concepts in surfaceenergy problem, in: Structure and properties of solid surfaces, edited by: Gomer, R. and Smith, C. S., 5-81, University of Chicago Press, Chicago, Illinois, 1953.

Heyraud, J. C. and Métois, J. J.: Establishment of the equilibrium shape of metal crystallites on a foreign substrate: Gold on graphite, J. Cryst. Growth, 50, 571-574, https://doi.org/10.1016/0022-0248(80)90112-8, 1980a.

Heyraud, J. C. and Métois, J. J.: Establishment of the equilibrium shape of gold crystallites on a graphite cleavage surface: Surface energies and interfacial energy, Acta Metall., 28, 1789-1797, https://doi.org/10.1016/0001-6160(80)90032-2, 1980 b.

Hintze, C.: Handbuch der Mineralogie, 1, Verlag Von Veit \& Comp., Leipzig, 197-217, 1904.

Jensen, F., Besenbacher, F., and Stengaard, I.: Two new oxygen induced reconstruction on $\mathrm{Cu}(111)$, Surf. Sci., 269-270, 400-404, https://doi.org/10.1063/1.4921258, 1992.

Jeong, H.-C. and Williams, E. D.: Steps on surfaces: experiment and theory: Surf. Sci. Rep., 34, 171-294, https://doi.org/10.1016/S0167-5729(98)00010-7, 1999.

Knight, P. J., Driver, S. M., and Woodruff, D. P.: Scanning tunneling microscopy investigation of the oxygen-induced faceting and "nano-faceting" of the vicinal copper surface, Surf. Sci., 376, 1-3, 374-388, https://doi.org/10.1016/S0039-6028(96)01328-3, 1997.

Krause, D. J.: The Making of a Mining District: Keweenaw Native Copper 1500-1870, Wayne State University Press, Detroit, ISBN 0-8143-2406-1, 1992.

Lahtonen, K., Hirsimäki, M., Lampimäki, M., and Valden, M.: Oxygen adsorption-induced nanostructures and island formation on $\mathrm{Cu}$ (100): Bridging the gap between the formation of surface confined chemisorption layer and oxide formation, J. Chem. Phys., 129, 124703, https://doi.org/10.1063/1.2980347, 2008.

Lankton, L.: Hollowed Ground: Copper Mining and Community Building on Lake Superior, 1840s-1990s, Wayne State University Press, Detroit, https://doi.org/10.2113/econgeo.105.7.1353, 2010 .
Legrand-Bonnyns, E. and Ponslet, A.: Pre-oxidation structures at $650{ }^{\circ} \mathrm{C}$ on $\mathrm{Cu}$ (100), (210) and (841) surfaces studied by RHEED and microscopy, Surf. Sci., 53, 675-688, https://doi.org/10.1016/0039-6028(75)90163-6, 1975.

Lian, X., Xiao, P., and Liu, R.: Calculations of oxygen adsorption-induced surface reconstruction and oxide formation on $\mathrm{Cu}(100)$, Chem. Mater., 29, 1472-1484, https://doi.org/10.1021/acs.chemmater.6b02722, 2017.

Liu, D.-J. and Thiel, P. A.: Oxygen and sulfur adsorption on vicinal surfaces of copper and silver: Preferred adsorption sites, J. Chem. Phys., 148, 123706, https://doi.org/10.1063/1.5021091, 2018.

McKee, C. S., Renny, L. V., and Roberts, M. W.: The adsorption of oxygen on $\mathrm{Cu}$ (210), Surf. Sci., 75, 92-108, https://doi.org/10.1016/0039-6028(78)90055-9, 1978.

Milne, R. H.: A RHEED study of oxygen adsorbed on copper, Surf. Sci., 121, 347-359, https://doi.org/10.1016/00396028(82)90247-3, 1982.

Niehus, N.: Surface reconstruction on $\mathrm{Cu}$ (111) upon oxygen adsorption, Surf. Sci., 130, 41-49, https://doi.org/10.1016/00396028(83)90258-3, 1983.

Niu, W. and $\mathrm{Xu}, \mathrm{G.:}$ Crystallographic control of noble metal nanocrystals, Nanotoday, 6, 265-285, https://doi.org/10.1016/j.nantod.2011.04.006, 2011.

Pimpinelli, A. and Villain, J.: Physics of Crystal Growth, Cambridge University Press, Cambridge, UK, https://doi.org/10.1017/CBO9780511622526, 1999.

Pollinger, F., Schmitt, S., Sander, D., Tian, Z., Kirschner, J., Vrdoljak, P., Stadler, C., Maier, F., Marchetto, H., Schmidt, T., Schöll, A., and Umbach, E.: Nanoscale patterning, macroscopic reconstruction, and stress by organic adsorption on vicinal surfaces, New J. Phys., 19, 013019, https://doi.org/10.1088/13672630/aa55b8, 2017.

Prévot, G., Crozet, B., Girard, Y., Coati, A., Garreau, Y., Hohage, M., Sun, L. D., and Zeppenfeld, P.: Elastic origin of the $\mathrm{O} / \mathrm{Cu}(110)$ self-ordering evidenced by GIXD, Surf. Sci., 549, 52, https://doi.org/10.1016/j.susc.2003.11.020, 2004.

Reinecke, N. and Taglauer, E.: The kinetics of oxygen-induced faceting of $\mathrm{Cu}(115)$ and $\mathrm{Cu}(119)$ surfaces, Surf. Sci., 454-456, 94-100, https://doi.org/10.1016/S0039-6028(00)00272-7, 2000.

Romé de L'Isle, J.-B.: Cristallographie, Imprimerie de Monsieur, Paris, 1783.

Sheppard, D. C., Parkinson, G. S., Hentz, A., Quinn, P. D., Munoz-Marquez, M. A., Woodruff, D. P., Bailey, P., and Noakes, T. C. Q.: Surface relaxation in $\mathrm{Cu}$ (410)-O: A medium energy ion scattering study, Surf. Sci., 604, 788-796, https://doi.org/10.1016/j.susc.2010.02.001, 2010.

Sotto, M.: Oxygen induced reconstruction of (h11) and (100) faces of copper, Surf. Sci., 260, 235-244, https://doi.org/10.1016/0039-6028(92)90037-7, 1992.

Sunagawa, I.: Crystals, Cambridge University Press, Cambridge, 2005.

Sundquist, B. E.: A direct determination of the anisotropy of the surface free energy of solid gold, silver, copper, nickel, and alpha and gamma iron, Acta Metall., 12, 67-86, https://doi.org/10.1016/0001-6160(64)90055-0, 1964.

Tremsin, A. S., Rakovan, J., Shinohara, T., Kockelmann, W., Losko, A. S., and Vogel, S. C.: Non-destructive study of bulk crystallinity and elemental composition of natural gold single crystal 
samples by energy-resolved neutron imaging, Sci. Rep.-UK, 7, 40759, https://doi.org/10.1038/srep40759, 2017.

Trepte, L., Menzel-Kopp, C. H. R., and Menzel, E.: Surface structures on spherical copper crystals after adsorption of oxygen, Surf. Sci., 8, 223-232, https://doi.org/10.1016/00396028(67)90084-2, 1967.

Verma, A. R.: Crystal growth and dislocations, Butterworths, London, 1953.

Vlieg, E., Driver, S. M., Goedtkindt, P., Knight, P. J., Liu, W., Lüdecke, J., Mitchell, K. A. R., Murashov, V., Robinson, I. K., de Vries, S. A., and Woodruff, D. P.: Structure determination of $\mathrm{Cu}(410)-\mathrm{O}$ using X-Ray diffraction and DFT calculations, Surf. Sci., 56, 16-32, https://doi.org/10.1016/S0039-6028(02)020666, 2002.

Wang, J. and Wang, S. Q.: Surface energy and work function of fcc crystals: Density functional study, Surf. Sci., 630, 216-224, 2014.

Wang, X., Jia, Y., Yao, Q., Wang, F., Ma, J., and Hu, X.: The calculation of the surface energy of high-index surfaces in metal at zero temperature, Surf. Sci., 551, 179-188, 2004.

Weege, R. J. and Pollack, J. P.: Recent developments in nativecopper district of Michigan. In: Proceedings of the Society of Economic Geologists Field Conference, 30 September-2 October 1971, Michigan Copper District, MI, USA, 18-43, 1971.
Williams, E. D.: Surface steps and surface morphology: understanding macroscopic phenomena from atomic observations, Surf. Sci., 299/300, 502-524, https://doi.org/10.1016/00396028(94)90678-5, 1994.

Wilson, M. L. and Dyl, S. J.: The Michigan Copper Country, Mineral. Rec., 23, 5-722, 1992.

Woll, C., Wilson, R. J., Chiang, S., Zeng, H. C., and Mitchell, K. A. R.: Oxygen on $\mathrm{Cu}$ (100) surface structure studied by scanning tunnelling microscopy and by low-energy-electron-diffraction multiple-scattering calculations, Phys. Rev. B, 42, 11926-11929, https://doi.org/10.1103/PhysRevB.42.11926, 1990.

Woodruff, D. P.: How does crystal grow? A commentary on Burton, Cabrera and Frank (1951) "The growth of crystals and the equilibrium structure of their surfaces": Philos. Trans. A, 373, 20140230, https://doi.org/10.1098/rsta.2014.0230, 2015.

Wulff, G.: Zur Frage der Geschwindigkeit des Wachsthums und des Auflösung der Kristalflächen, Z. Kris. Min., 34, 449-530, https://doi.org/10.1524/zkri.1901.34.1.449, 1901. 